\title{
Caracterização anatomopatológica da papilomatose cutânea em bovinos leiteiros
}

\author{
Anatomopathologic caracterization of cutaneous papillomatosis \\ in dairy Cattle
}

Ana Paula Iglesias Santin," Luiz Augusto Batista Brito**

\begin{abstract}
Resumo
Foram realizadas seis colheitas de papilomas cutâneos por animal, em 40 bovinos, em diferentes momentos, perfazendo um total de 240 amostras, para o estudo histopatológico dos mesmos. Esses bovinos estavam sendo submetidos a diferentes tratamentos para papimatose cutânea. Os papilomas pedunculados foram caracterizados por hiperceratose intensa, hiperplasia da epiderme, hiperplasia de fibroblastos, sendo as fibras colágenas mais abundantes e densas que as dos papilomas planos. Estes mostraram hiperceratose mais leve que os papilomas pedunculados, sendo a fibroplasia dérmica mínima ou ausente. Em ambos os tipos de papilomas durante a fase de regressão foi observada discreta hiperplasia da epiderme e reduzida hiperceratose.
\end{abstract}

Palavras-chave: bovino, papilomatose, papilomavírus.

\begin{abstract}
During an evaluation of different treatments of bovine cutaneous papillomatosis, six papillomas samples from each bovine, were collected in different times for histopathologic studies. Forty animals were used in this experiment, with a total amount of 240 papillomas samples. The pedunculated papillomas showed intense hyperkeratosis, epidermal hyperplasia, fibroblastic hyperplasia, and the collagen fibre was abundant and dense when compared to atypical papilomas. The atypical papillomas showed mild hyperkeratosis and minimal dermal fibroplasia. Both papillomas types showed a reduced epidermal hyperplasia and hyperkeratosis during regression.
\end{abstract}

Keywords: Bovine, papillomatosis, papillomavirus

\section{Intodução}

A papilomatose cutânea bovina é uma enfermidade infectocontagiosa, de origem viral, crônica, de caráter tumoral benigno e de natureza fibroepitelial, caracterizando-se por tumores que se localizam na pele e mucosa (Richtzenhain e Ribeiro, 1982), constituindo-se um problema grave e constante em rebanhos leiteiros no estado de Goiás.

De acordo com Lancaster e Olson (1982), Blood e Radostits (1991), verrugas topograficamente específicas, que se caracterizam por uma estrutura macro e microscopicamente particular, são causadas por tipos de papilomavírus distintos, sendo que seis destes vírus foram identificados e classificados em: PVB 1 (Papilomavírus bovino 1) a PVB 6.

O papilomavírus infecta células basais do epitélio, resultando em hiperplasia das células da camada espinhosa e acantose, acompanhadas de hiperceratose (Lancaster e Olson, 1982). Conseqüentemente, o tecido conjuntivo subjacente acompanha o mesmo processo que ocorre no epitélio, tanto pela ação do estímulo viral como para nutrir e suportar mecanicamente a hiperplasia do tecido epitelial (Corrêa e Corrêa, 1992). Fujimoto e Olson (1966) estudaram a histopatologia de cinco fibropapilomas, verificando severa hiperplasia acompanhada de moderada paraceratose da epiderme. Na camada granulosa e espinhosa observaram vacuolização do núcleo e citoplasma celular e inclusões acidofílicas significativas.

De acordo com Somvanshi et al. (1988), na regressão de fibropapilomas há severa infiltração de células mononucleares e a presença de linfócitos tanto no epitélio quanto na derme é proporcional ao grau de regressão, ou seja, quanto mais avançada esta estiver, maior quantidade de linfócitos é encontrada.

O objetivo do presente trabalho foi caracterizar morfologicamente os diversos tipos de papilomas cutâneos presentes nos rebanhos leiteiros no estado de Goiás, enquanto estes animais estavam sendo submetidos a tratamento, visando, desta forma, a melhor indicação terapêutica.

\footnotetext{
* Escola de Veterinária - Universidade Federal de Goiás/UFG. Caixa Postal 131 - Campus II, CEP 74001-970. Goiânia, GO - Brasil. E-mail:apis@ vet.ufg.br

** Escola de Veterinária - Universidade Federal de Goiás/UFG. Caixa Postal 131 - Campus II, CEP 74001-970. Goiânia, GO - Brasil. E-mail:labbrito@vet.ufg.br
} 


\section{Material e métodos}

As propriedades escolhidas tinham no seu plantel animais de aptidão leiteira acometidos pela papilomatose cutânea bovina e estavam localizadas em um raio de até 200 quilômetros a partir dos limites do município de Goiânia.

Foram utilizados 40 bovinos de aptidão leiteira, portadores de diferentes tipos de papilomas cutâneos (pedunculado, plano e misto - ambos ao mesmo tempo) e classificados em diferentes graus de papilomatose (leve, moderado e intenso). Estes animais foram mantidos nas respectivas propriedades e submetidos a uma criteriosa e detalhada avaliação clínica das grandes funções no início do experimento, a fim de descartar-se a existência de outras enfermidades ou deficiência física que pudessem interferir nos resultados.

Os animais foram divididos em cinco grupos de tratamentos, sendo estes a autovacina, a auto-hemoterapia, o levamisole, o clorobutanol e a diaminazina.

As amostras de papilomas cutâneos eram de diferentes tipos (planos e pedunculados) e tamanhos, localizados em. diversas regiões do corpo do animal. As verrugas foram previamente lavadas com água e sabão neutro e, posteriormente, foi realizada a extirpação de forma asséptica.

As amostras de papilomas colhidas (240 no total) foram fixadas, por no mínimo 24 horas, em solução de formol tamponado a $10 \%$, na proporção de 20 vezes o volume do fixador em relação ao volume das peças. Após a fixação, os fragmentos foram lavados em água corrente por cinco minutos, iniciando-se assim o processo de desidratação em álcool etílico, em série crescente de $70 \%$ até álcool absoluto. Posteriormente procedeu-se à clarificação com xilol e inclusão em parafina histológica com ponto de fusão a $56^{\circ} \mathrm{C}$. Na etapa seguinte, os papilomas foram seccionados com uma espessura de 3 a 5 micrômetros, em micrótomo rotativo, ${ }^{1}$ utilizando-se navalhas descartáveis. ${ }^{2}$ Os cortes obtidos de todos os papilomas colhidos foram corados pela técnica de hematoxilina e eosina (Luna, 1968).

A leitura foi realizada em fotomicroscópio óptico de campo claro. ${ }^{3}$ Blocos selecionados de papiloma foram laminados a 3 micrômetros e processados para utilização em técnicas histológicas especiais, onde utilizou-se a seguinte coloração especial: Tricrômico de Masson para fibras elásticas, segundo a descrição de Vêncio (2000), obtendo como resultado da coloração, fibras elásticas azul-escuro, núcleos de azul a preto, colágeno rosa a vermelho e outros elementos em amare10.

O processamento histopatológico foi realizado no Laboratório de Histopatologia do Setor de Patologia Animal do Departamento de Medicina Veterinária da Escola de Veterinária da Universidade Federal de Goiás.

\footnotetext{
1 American Optical ${ }$, modelo Spencer 820 - EUA

${ }^{2}$ Leica Instruments ${ }^{\circledR}$, modelo 818 - EUA

${ }^{3}$ Carl Zeiss $®$, modelo Jenaval - Alemanha Oriental
}

\section{Resultados}

O aspecto macroscópico dos papilomas pedunculados caracterizou-se por uma base de inserção ampla, apresentando-se estreita em alguns casos. A superfície era irregular, cornificada, dura e sem a presença de pêlos, mostrando uma coloração acinzentada a negra e seu tamanho variou entre 1 a 10 centímetros de diâmetro. A aparência destas verrugas assemelhava-se à de uma couve-flor; podendo formar grandes massas de confluência tumoral. Os papilomas mais escuros e bastante queratinizados destacavam-se da pele com maior facilidade, bastando uma pequena torção na base de inserção para serem retirados.

Observou-se que quando a papilomatose regredia, os papilomas caiam, às vezes auxiliados pela presença de miíases, onde as larvas consumiam o tecido do próprio papiloma. As verrugas menores normalmente apresentavamse mais ressecadas e regrediam de tamanho, achatando-se até desaparecerem por completo; durante este processo podiam ser confundidas com papiloma do tipo plano; no entanto, eram mais cornificadas. A maioria dos papilomas escuros, ao passarem pelo processo de ressecamento, tornavam-se mais claros.

Já o papiloma plano era achatado, com base de inserção ampla, caracterizando-se por lesões circulares, que na maioria dos casos cobriam longas áreas do corpo do bovino. A coloração destes variou entre o branco e o negro. Distintamente do pedunculado o papiloma plano apresentava pêlos, seu tamanho variava entre meio a seis centímetros de diâmetro, não se destacando da pele com facilidade, sendo necessária a intervenção cirúrgica. A regressão deste tipo de papiloma caracterizou-se por um ressecamento com posterior descamação e esfacelamiento; embora também tenha sido verificado em alguns casos uma redução do tamanho da verruga, tornando-se més achatada e mais clara, até o seu desaparecimento. Neste último processo, os pêlos adjacentes começavam a cobrir os papilomas, ficando com aspecto de pêlos eriçados nestas regiões, em forma de tufos.

O aspecto microscópico comum ao papiloma pedunculado e ao plano, observados neste experimento, foi caracterizado por hiperplasia das células epiteliais, com acantose, acompanhada por hiperceratose ortoceratótica na maioria dos casos, sendo a espessura da camada córnea variável (Figuras 1 e 2). No estrato espinhoso observaram-se alterações degenerativas nas células da epiderme, como a presença isolada ou focal de células com vacuolização intracitoplasmática (degeneração hidrópica), o que permitiu a perda da afinidade tintorial do citoplasma, impelindo um aspecto pálido a estas células. No estrato granuloso normal é possível visualizar alguns grânulos basofílicos intracitoplasmáticos nas células desta camada (Banks, 1991); no entanto, na papilomatose cutânea, verificouse um aumento na quantidade destas granulações, que atingiam até as células do estrato espinhoso da epiderme (Figura 4). A disceratose também foi um achado comum ao observarse a epiderme do papiloma (Figura 3). Estas alterações histopatológicas variaram em intensidade de um papiloma para outro. 


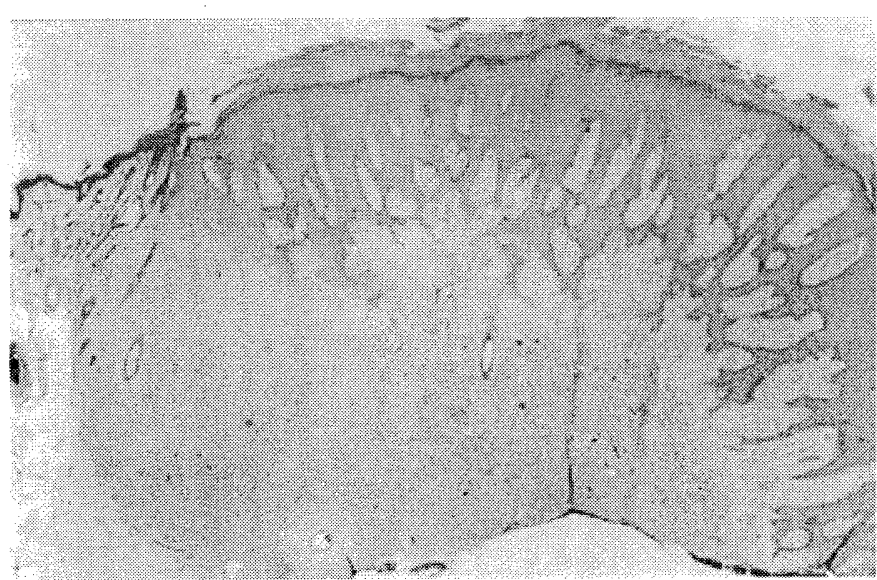

Figura 1 - Papiloma cutâneo bovino, do tipo pedunculado. hiperceratose e hiperplasia de células da epiderme e fibroplasia. Desorganização das cristas interpapilares. Ausência de folículos pilosos e glândulas na derme. $H \& E \times 6,4$

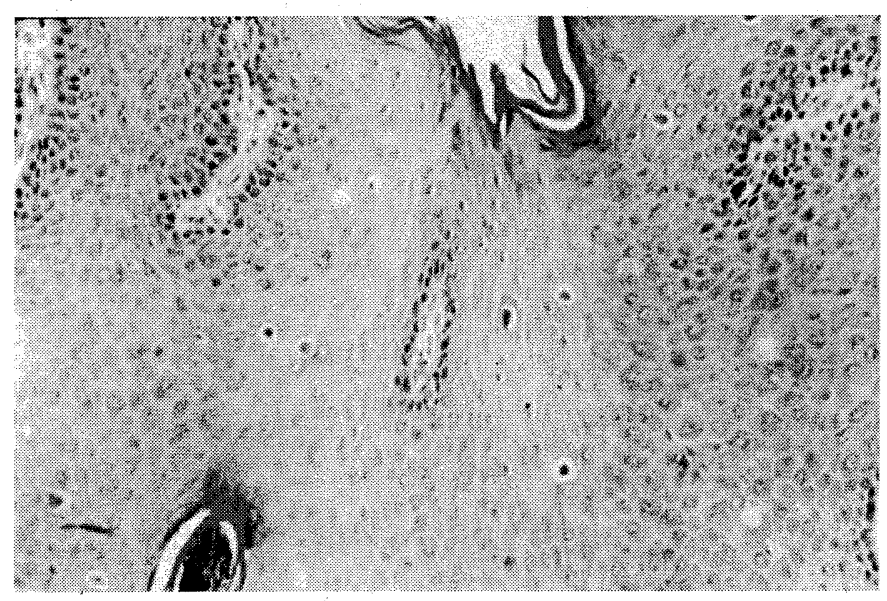

Figura 3 - Papiloma cutâneo bovino. Presença de disceratose. H\&E $\times 50$

O papiloma pedunculado mostrou uma hiperceratose intensa e as projeções das cristas papilares para o interior da derme eram bastante profundas e desorganizadas. Além da hiperplasia da epiderme, verificou-se uma hiperplasia dos fibroblastos, levando a um aumento da espessura da derme que se projetava para o interior da epiderme através das papilas dérmicas. O tecido conjuntivo da derme normal foi substituído por um crescimento fibromatoso, não se verificando a presença de glândulas nem de folículos pilosos, descaracterizando-a dos padrões de normalidade. As fibras colágenas mostraram-se mais abundantes e mais densas na derme dos papilomas pedunculados que na dos papilomas planos, o que pôde ser constatado através da coloração especial pelo Tricômico de Masson (Figura 5).

Os papilomas em fase de regressão ainda apresentaram discreta hiperplasia da epiderme e pequena hiperceratose. Não foi observada a presença de infiltrados de células mononucleares no tecido conjuntivo da derme ou no tecido epitelial destas verrugas.

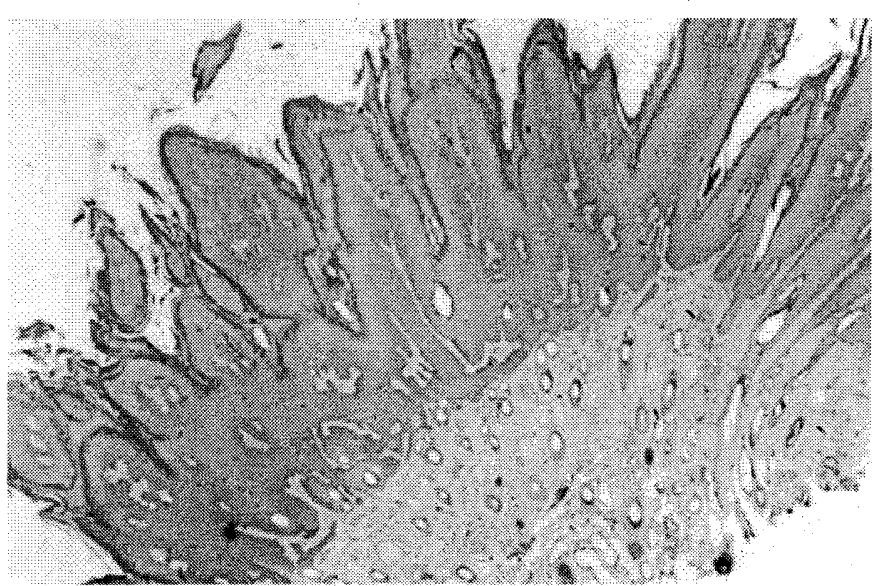

Figura 2 - Papiloma cutâneo bovino, do tipo plano. Hiperceratose, hiperplaisa da epiderme, folículos pilosos e glândulas no tecido conjuntivo da derme. H\&E X 6,4

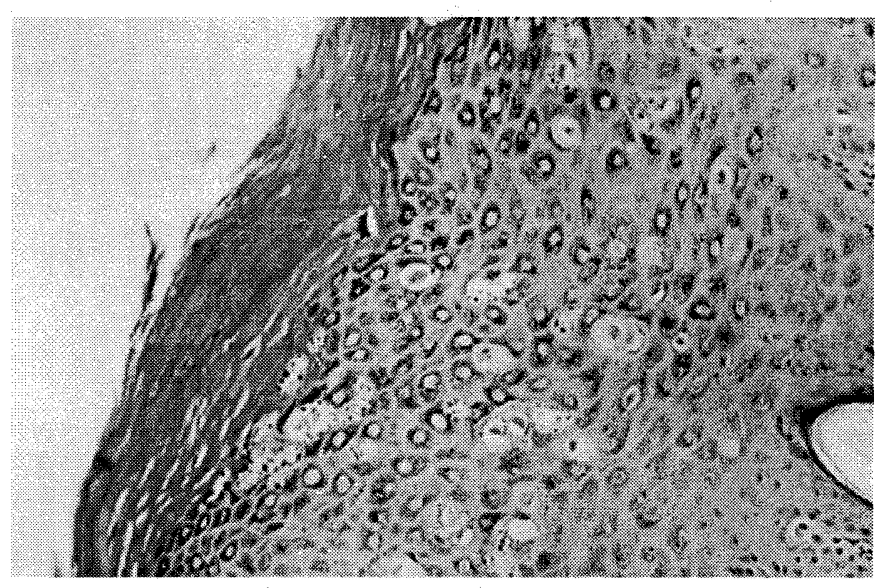

Figura 4 - Papiloma cutâneo bovino. Granulações basofílicas intracitoplasmáticas e vacuolização citoplasmática. H\&E X 25

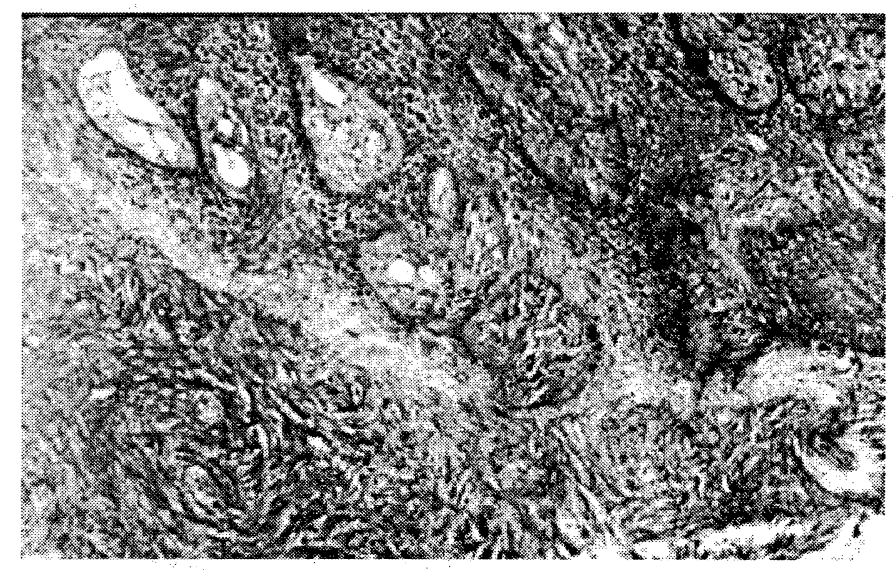

Figura 5 - Papiloma cutâneo bovino, do tipo pedunculado. Intenso aumento de fibras colágenas na derme. Masson X 25 
Por outro lado, o papiloma plano mostrou uma hiperceratose mais leve, quando comparada à do papiloma pedunculado, e as cristas interpapilares estendiam-se mais superficialmente e de forma organizada para o interior da derme. Os órgãos anexos contidos na derme continuaram presentes e funcionais e a fibroplasia dérmica foi mínima ou ausente. A presença de uma grande quantidade de eosinófilos na derme foi um achado constante durante o estudo histopatológico destes papilomas, fato atribuído a constante ectoparasitose, à qual estes animais estavam expostos durante todo o experimento, sendo, portanto, um achado previsível. O papiloma plano apresentou fibras colágenas em menor quantidade e menos densas do que o observado nos papilomas pedunculados (Figura 6). Na fase de regressão ainda apresentaram discreta hiperplasia da epiderme e pequena hiperceratose. Neste tipo de papiloma também não foi observado nenhum tipo de infiltrado de células mononucleares, na derme ou na epiderme.

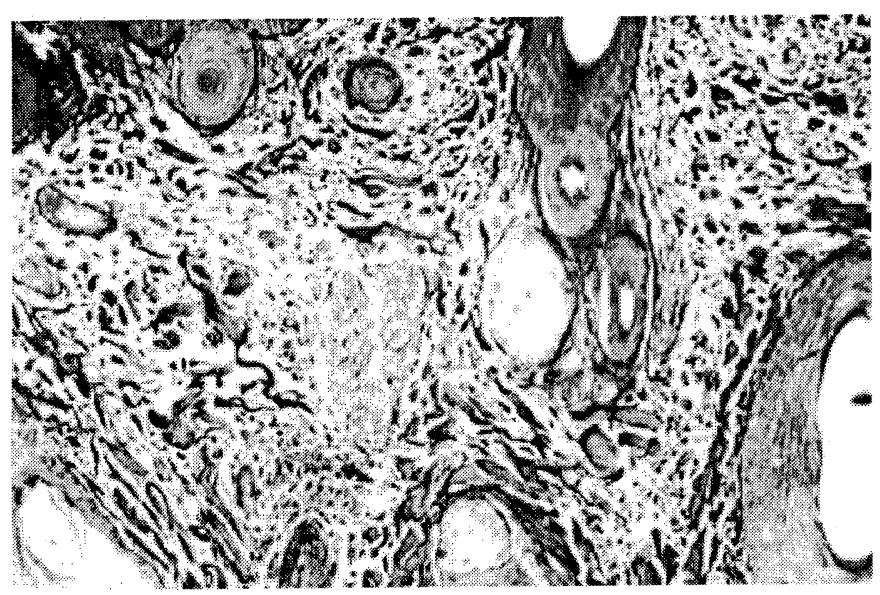

Figura 6 - Papiloma cutâneo bovino, do tipo plano. Discreto aumento das fibras colágenas na derme. Masson X 50

Durante todo o experimento não foi observada influência dos tratamentos no aspecto histopatológico, nem mesmo durante o processo de regressão, razão pela qual os tratamentos não foram descritos.

\section{Discussão}

O aspecto macroscópico do papiloma pedunculado descrito neste estudo foi semelhante aos apresentados por inúmeros outros autores tais como: Dal Molin Capellaro et al. (1978), Richtzenhain e Conrado Ribeiro (1982), Somvanski et al. (1988), Gupta et al., 1989, que descreveram o papiloma do tipo pedunculado com aspecto de couve-flor, base de inserção ampla ou estreita, superfície irregular, cornificado e com uma coloração variando entre o cinza e o preto, não possuindo pêlos e de tamanho variável.

O papiloma do tipo plano observado macroscopicamente apresenta aspectos macroscópicos semelhantes àqueles descritos por Richtzenhain e Conrado Ribeiro (1982), onde o papiloma plano apresenta uma forma achatada, com base ampla, de coloração esbranquiçada e com presença de pêlos, podendo cobrir largas áreas do corpo do animal e sendo de difícil remoção. No entanto, nenhum dos autores mencionados anteriormente descrevem papilomas planos com coloração preta, como pôde ser observado no presente estudo. O esbran-quiçamento, a esfoliação e a diminuição do tamanho dos papilomas na fase de regressão são achados que também foram descritos por Carvalho et al. (1968).

A maioria dos autores pesquisädos concorda que, ao observar-se microscopicamente os papilomas, encontram-se acantose e hiperceratose características da doença (Dal Molin Capellaro et al. 1978, Gupta et al. 1989, Fujimoto e Olson, 1966, Wadhwa et al. 1996).

Dal Molin Capellaro et al. (1978) descrevem que as cristas interpapilares do tecido epitelial penetram profundamente no interior da derme, em papilomas pedunculados. Dal Molin Capellaro et al. (1978), Lancaster e Olson (1982), mencionam que no tecido conjuntivo da derme há uma proliferação fibroblástica, fazendo com que a derme normal seja substituída por um fibroma, vindo a confirmar os achados histopatológicos descritos no presente estudo, que também comprovam a intensa reação fibroblástica através da utilização de coloração especial.

Já o papiloma plano como observado neste experimento, é caracterizado histopatologicamente por Dal Molin Capellaro et al. (1978), por apresentar cristas interpapilares que se estendem superficialmente para o interior da derme, sendo que o tecido conjuntivo da derme sofre pequena ou nenhuma fibroplasia, fato comprovado pela coloração especial para fibras colágenas, e onde pode-se observar os anexos da epiderme normais.

Nos dois tipos de papilomas estudados verificou-se a presença de vesículas intracitoplasmáticas (degeneração hidrópica) em células do estrato espinhoso, que sugerem o efeito citopático do vírus, achado este também relatado por Dal Molin Capellaro et al. (1978), Fujimoto e Olson (1966). Outra característica observada foi o aumento na quantidade de granulações basofílicas, intracitoplasmáticas e intranucleares, no estrato granuloso, sendo que estas acabavam por estender-se até o estrato espinhoso, o que corrobora com as descrições de Dal Molin Capellaro et al. (1978). Já Gupta et al.(1989) mencionam em seus trabalhos a presença de inclusões eosinofílicas intranucleares, enquanto Fujimoto e Olson (1966) descrevem a presença de inclusões acidofílicas intracitoplasmáticas. A disceratose presente na epiderme do tecido papilomatoso descrita por Lee e Olson (1969) em seu estudo, também foi observada no presente experimento.

\section{Conclusão}

Através do exame anatomo-histopatológico pôde-se estabelecer uma classificação morfológica para os diferentes tipos de papilomas enconirados neste experimento. 


\section{Referências}

BLOOD, D. C.; RADOSTITS, O. M. Clínica veterinária. 7. ed. Rio de Janeiro: Guanabara Koogan, 1991. 1264 p.

CARVALHO, F. V.; PEREIRA, P. C.; BIRGEL, E. H. Tratamento da papilomatose bovina pelo diaceturato do di(4-amidinofenil)-(N-1,3)triazeno). Faculdade de Medicina Veterinária da USP, 1968, $5 \mathrm{p}$.

CORRÊA, W. M.; CORRÊA, C. N. M. Enfermidades infecciosas dos mamíferos domésticos. 2. ed. Rio de Janeiro: Medsi, 1992. 843 p.

DALMOLINCAPPELARO, C. E. M. P.; RIBEIRO, L. O. C.; MUELLER, S. B. K.; PIEGAS, N. S. Estudo da morfologia e histopatologia de diferentes tipos de papilomas bovinos. Biológico, v. 44, p. 307-316, 1978.

FUJIMOTO, Y.; OLSON, C. The fine structure of the bovine wart. Pathol Vet, v. 3, n. 6, p. 659-684, 1966.

GUPTA, M. P.; GUPTA, P. P.; RATHORE, S. S.; GUPTA, A. K. Bovine cutaneous papillomatosis - a case report. Indian Vet J, v. 66, p. 358359, abr. 1989.

LANCASTER, W. D.; OLSON, C. Animal papillomaviruses. Microbiol Reviews, v. 46, n. 2, p.191-207, 1982.
LEE, K. P.; OLSON, C. Histochemical studies of experimentaly produced bovine fibropapillomas. J Investigative Dermatol, v. 52, n. 5, p. 454464, 1969.

LUNA, L. G. Manual of histologic staining methods of the armed forces institute of pathology. 3. ed. New York: McGraw-Hill, 1968, 258 p.

RICHTZENHAIN, L. J.; CONRADO RIBEIRO, L. O. Papilomatose bovina (verruga-figueira). Rev Bras Med Ve., v. 5, n. 3, p. 7-11, 1982.

SOMVANSHI, R.; SHARMA, B.; KOUL, G. L.; BISWAS, J. C.; YADAV, M. $P$. The delayed cutaneous hypersensitivity and humoral immune response in spontaneous bovine papillomas. Indian Vet Med J, v. 12, p. 7-14, mar. 1988.

VÊNCIO, I. Técnicas histológicas empregadas no Departamento de Anatomia Patológica da Faculdade de Ciências Médicas da Unicamp. Departamento de Anatomia Patológica da Faculdade de Ciências Médicas da Unicamp, s.d. (Online, 15 de setembro de 2000, Internet: http:/ /www. Fern.unicamp.br/ deptos/ anatpat/tec. html).

WADHWA, D. R.; PRASAD, B.; RAO, V. N.; DHALIWAL, A. S. Clinicotherapeutic and histopathologic studies on bovine cutaneous papillomatosis. Indian J Diary Sci, v. 49, n. 3, p. 206-208, 1996. 